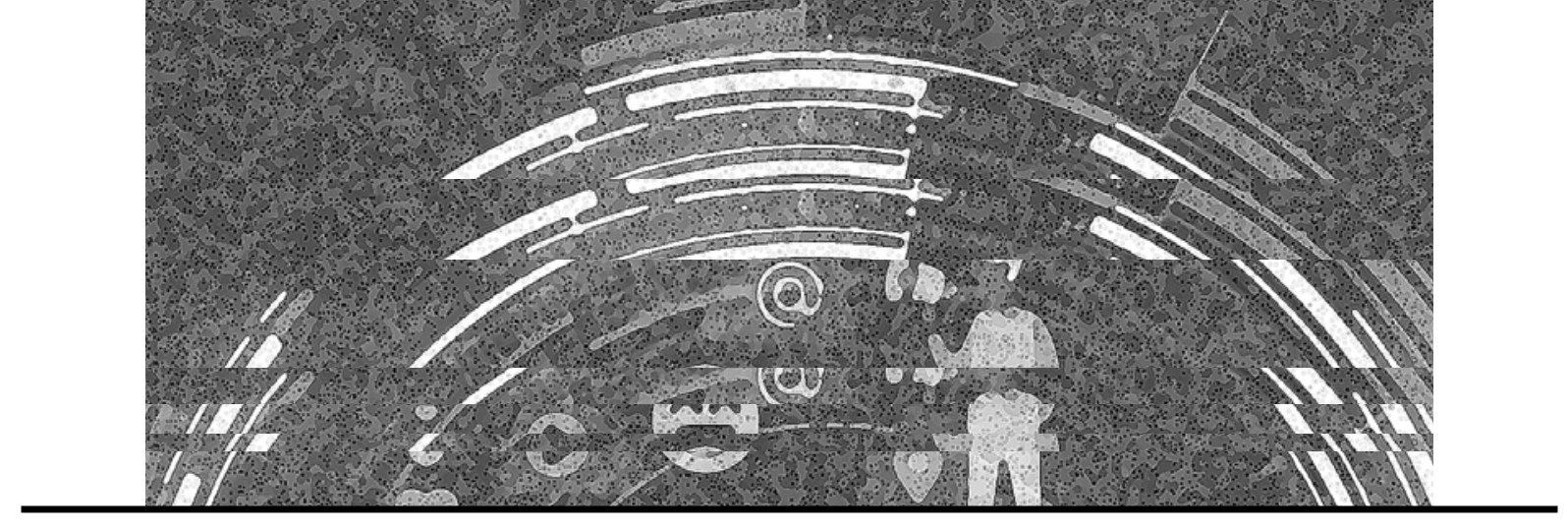

\title{
LA EXPERIENCIA EN FACEBOOK DE JÓVENES UNIVERSITARIOS Y SUS LÓGICAS DE ACCIÓN ONLINE
}

THE FACEBOOK EXPERIENCE OF YOUNG UNIVERSITY STUDENTS AND THEIR ONLINE ACTION LOGICS

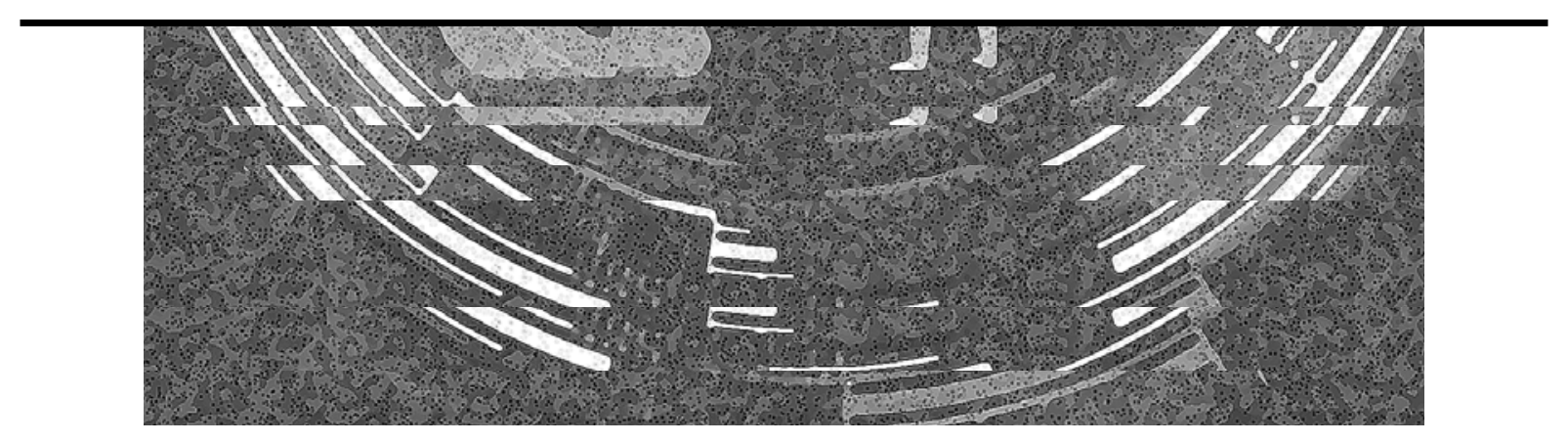

DOI: $10.25100 /$ nc.v0i29.11612

Jhon Jaime Velasco ${ }^{1}$

Universidad del Valle, Cali Colombia.

jhon.velasco.arboleda@correounivalle.edu.co ORCID: 0000-0003-3194-0583

Recibido: 2 de junio de 2020

Aprobado: 8 de febrero de 2021

ISSN en línea 2539-4355 / ISSN impreso 1900-9909 Este trabajo está bajo la licencia Creative Commons BY NC SA 4.0.

¿Cómo citar este artículo? / How to quote this article?

Velasco, J.J. (2021). La experiencia en Facebook de jóvenes universitarios y sus lógicas de acción online. Nexus, (29), 1-20. https://doi.org/10.25100/nc.v0i29.11612 
Resumen: El artículo da cuenta del análisis de la experiencia y el proceso de individuación de un conjunto de jóvenes universitarios de la ciudad de Cali, durante los meses de enero a junio del año 2017, que utilizaron la red socio digital Facebook como un espacio para la presentación en público de su vida, articulando tres lógicas de acción expuestas por Danilo Martuccelli y François Dubet: integración, estrategia y subjetivación. Por ello, se realizó un estudio etnográfico de la actividad desarrollada en perfiles Facebook de 20 estudiantes de distintas universidades de la ciudad, complementando con entrevistas semiestructuradas y un grupo focal para contrastar las observaciones etnográficas realizadas. Al finalizar, se sugiere que el estudio se aproxima al modo en que estos jóvenes se constituyen como individuos, procurándose experiencias con sentido en una ciudad llena de incertidumbres, al tiempo que configuran dinámicas de vínculo, protección de su autonomía y usos de la red socio digital para garantizarse beneficios en la conectividad.

Palabras claves: Individuación, Facebook, Jóvenes universitarios, Lógicas de acción.

\begin{abstract}
The article gives an account of the analysis of the experience and the process of individuation of a group of young university students from the city of Cali, during the months of January to June 2017, who used the social network Facebook as a space for presentation in audience of his life, articulating three logics of action exposed by Danilo Martuccelli y François Dubet: integration, strategy and subjectivation. Therefore, an ethnographic study was carried out of the activity carried out on Facebook profiles of 20 students from different universities in the city, complemented with semi-structured interviews and a focus group to contrast the ethnographic observations made. At the end, it is suggested that the study approaches the way in which these young university students constitute themselves as individuals, seeking meaningful experiences, in a city full of uncertainties; while configuring link dynamics, protection of their autonomy and uses of the social network to ensure benefits in connectivity.
\end{abstract}

Keywords: Individuation, Facebook, University students, Action logics.

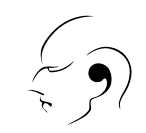

\title{
Origen del artículo
}

Este artículo de investigación presenta los resultados del trabajo en maestría en sociología titulado "Facebook como experiencia. Jóvenes universitarios y lógicas de acción online”, realizado con el apoyo del Grupo de Investigación Acción Colectiva y Cambio Social de la Universidad del Valle. 


\section{Introducción}

Actualmente el crecimiento de las nuevas tecnologías, las facilidades de acceder a Internet y el uso de las redes socio digitales $^{2}$ (Facebook, WhatsApp, Snapchat, Instagram, Twitter), facilita las maneras de relacionarse. Cada vez más, millones de personas pasan horas enteras frente a las pantallas de sus smartphones o computadores conociendo lugares del mundo, buscando respuestas a dudas e inquietudes, comunicándose con seres queridos o amigos, jugando online, divirtiéndose con memes de internet, compartiendo selfies o tratando de encontrar una pareja compatible por alguna página web de citas o aplicaciones móviles de citas (OKCupid, Badoo y Match. com, Tinder, Grindr). De ahí que algunos autores como Sibila (2008), Jaurégüiberry \& Proulx (2011), Turkle (2011), Serrano, (2012), Winocur (2012) Morduchowicz (2012), (Reguillo, 2012), (Gómez, González, Rueda, \& Valencia , 2016), (Lemus, 2017), (Lasén Díaz, 2019), (Moreno, 2020), (Pérez \& Montoya Gastelún, 2020), entre otros, se hayan interesado por analizar el uso de las tecnologías para dar cuenta de nuestro comportamiento como seres sociales y las relaciones que establecemos mediante dispositivos móviles ante la emergencia de un nuevo tipo de sociedad en la que el desarrollo de las plataformas socio digitales ha permeado las maneras de relacionarse y de presentarse en internet.

En este sentido, la investigación que soporta este artículo buscó conocer el individuo que está configurándose en Cali, desde la experiencia de uso que realizan jóvenes universitarios de la red socio digital Facebook. En la actualidad ser joven es vivir en un mundo donde los riesgos sociales y de salud (criminalidad, narcotráfico, adicciones, enfermedades) y la falta de expectativas laborales, amenazan los proyectos de vida, lo cual lleva a la búsqueda de nuevas significaciones para la conformación de una identidad, la realización de sueños y una vida productiva (Briceños, 2012). Por tanto, aquí se elabora un análisis preliminar respecto a cómo los jóvenes en Facebook dan cuenta de fragmentos de su vida que permiten comprender la sociedad contemporánea en la que nos encontramos y entrever cómo la experiencia de usar la tecnología genera relaciones interdependientes ("soportes") para sobrellevar las tensiones de nuestras sociedades y los retos que nos presenta la cotidianidad ("pruebas sociales"). Se parte de la idea de que en la sociedad actual los individuos necesitan de actividades que les ayuden a amortiguar la soledad, el aburrimiento, el riesgo y la incertidumbre que trae consigo la modernidad (Giddens et al., 1997; Beck, 1998; Bauman, 2003). En este caso, Facebook representaría un lugar desde donde actuar y encontrar estabilidad ante el incremento de los malestares que genera vivir en el mundo hoy. 
Cabe resaltar que no solo la población más joven universitaria es la que está buscando por sí misma soportes y generando nuevas prácticas sociales mediante redes socio digitales y dispositivos móviles. Actualmente, las posibilidades de internet y las redes socio digitales están abiertas a todas las personas, independiente de su edad. Sin embargo, son los jóvenes los más propensos a su uso. Según Data Reportal (2021), para el año 2020, el 57,3 \% de la población colombiana entre los 18 a 34 años de edad usó Facebook, Instagram y Facebook Messenger. Además, los datos indican que el 97.8 \% de la población entre los 16 a 64 años de edad ingresó a Facebook a través de su teléfono móvil. Para el año 2021 el ingresó a la red socio digital fue del 55,2\% entre los 18 a 34 años de edad mientras que el acceso a través de teléfonos móviles fue del $98.5 \%$. Por lo anterior, se puede decir que gran parte de la población joven de Colombia mantiene un perfil virtual en Facebook por sus posibilidades de comunicación, acceso a información y entretenimiento.

En este sentido, se asumió que gran parte de los jóvenes universitarios usan Facebook, acorde a sus intereses, como un espacio para la comunicación constante y la presentación en público de su vida social y/o exposición del yo, a través de las publicaciones (fotos, vídeos, comentarios, estados de ánimo, etc.) y demás actividades que realizan en su perfil virtual a modo de presentación reflexiva de sí mismos. Por consiguiente, se articuló el concepto de experiencia propuesto por Dubet \& Martuccelli (1998), e implementado por Jaurégüiberry \& Proulx (2011) en sus estudios acerca de los usos de las tecnologías de comunicación, para entender de manera más cercana las dinámicas y usos reflexivos que generaban los jóvenes universitarios, en tanto individuos, en la red socio digital con sus pares.

En cuanto a lo metodológico, el estudio realizó una revisión etnográfica de la actividad de perfiles virtuales de estudiantes universitarios desde la perspectiva de la etnografía virtual planteada por Hine $(2000)^{5}$. El estudio consideró tres fases:

1. Selección de jóvenes universitarios participantes. Mediante la estrategia de "bola de nieve" se vincularon al estudio estudiantes entre tercer y décimoprimer semestre para un total de 20 participantes. La mayoría residían en la ciudad de Cali, pocos casos venían de otras ciudades. Se encontraban entre los 17 y 28 años de edad; 13 mujeres y 7 hombres. Hubo mayor cantidad de participantes mujeres debido a que estas manifestaron más interés en comunicar su experiencia con la plataforma Facebook al momento de realizar la selección. No se tuvo ningún estudiante con pertenencia étnica interesado en participar y, aunque la mayoría de los participantes fueron heterosexuales, se vinculó una chica abiertamente lesbiana. Los participantes fueron de 8 universidades de Cali (Universidad delValle, Icesi, Universidad Santiago de Cali, Autónoma de Occidente, Universidad católica, Javeriana, Universidad San Martin, Escuela Nacional del Deporte) pertenecientes a las siguientes carreras: Recreación, Profesional del deporte, Comunicación social, Publicidad, Comunicación publicitaria, Lenguas extranjeras, Administración de empresas, Contaduría Pública, Derecho, Química Farmacéutica, 
Ingeniería en sistemas, Ingeniería industrial, Ingeniería civil, Sociología, Ciencias sociales, Psicología y Medicina. Es importante mencionar que los jóvenes participantes diligenciaron un consentimiento informado en que se les indicó los objetivos del proyecto, las condiciones de participación, los requerimientos de la investigación y el manejo de los datos de sus perfiles virtuales que iban a ser recolectados.

2. Seguimiento de la experiencia en Facebook desde las tres lógicas de acción. Se realizó un seguimiento durante los tres primeros meses del año 2017 documentando la relación entre cambios, recurrencias y particularidades de las actividades y contenidos de los perfiles virtuales de los jóvenes en Facebook. Para esto se usaron fichas de registro que articularon las tres grandes lógicas estructurales de acción (Dubet \& Martuccelli, 1998). A cada joven se le realizaron cuatro seguimientos teniendo en cuenta el tiempo social (días entre semana a fines de semana y viceversa) y los eventos de la vida personal (cumpleaños, rupturas amorosas, enfermedad, cambios en los ciclos escolares, etc.) que podían afectar (o no) las formas y decisiones de las publicaciones en los perfiles virtuales. Además, en ocasiones se realizaron preguntas a los participantes del estudio vía chat de Facebook en busca de sus apreciaciones y motivaciones acerca de su actividad en sus perfiles virtuales. En algunos casos se obtuvo respuesta inmediata por parte de los jóvenes y en otras ocasiones las respuestas tardaron horas o días, lo cual implicó que la obtención de la información fuera prolongada. Como producto de este ejercicio se consiguieron trayectorias de la experiencia de los jóvenes en Facebook que dieron cuenta de la articulación de las tres lógicas de acción a los tipos de publicaciones, imágenes, comentarios, y circunstancias que explicaban su actividad online.

3. Entrevistas y grupo focal de la experiencia en Facebook. Frente a la naturaleza cambiante de la red socio digital y la poca o mucha actividad de los perfiles virtuales de los jóvenes, se realizaron tres entrevistas y un grupo focal para contrastar y obtener información extra sobre eventos de la vida personal o social que no eran posibles de rastrear a través de sus perfiles virtuales y podían o no afectar su actividad online. Como producto de esta fase se obtuvo información que permitió enriquecer las observaciones etnográficas realizadas en la fase anterior y enriquecer, principalmente, los hallazgos de lógicas de subjetivación de los jóvenes en Facebook.

En consecuencia, el artículo desarrolla los siguientes asuntos: en la primera parte expone la interpretación conceptual de la noción de experiencia desde las tres lógicas de acción (integración, estrategia, subjetivación) y cómo estas fueron asumidas para la realización del estudio. En un segundo apartado presenta los resultados del análisis de estas tres lógicas de acción aplicadas al universo online de los estudiantes en Facebook. Finalmente, realiza unas conclusiones con la intención de contribuir al conocimiento del tipo de individuo que se está formando entre los jóvenes universitarios residentes en la ciudad de Cali a partir de la experiencia con las tecnologías. 


\section{La experiencia de los jóvenes universitarios en Facebook}

Para Dubet \& Martuccelli (1998) los individuos están sometidos a una prueba permanente, que designan con el término de experiencia y se caracteriza por el esfuerzo que hacen los actores por vincular y combinar tres grandes lógicas estructurales de acción: integración, estrategia y subjetivación.

La lógica de la integración que alude a la relación entre subjetividad, procesos de socialización e integración social, se ocupa de las instituciones y las formas de cómo los individuos se procuran relatos de formas de encuentro y adhesión social (sentido de pertenencia). Para el caso que ocupó el estudio, se asumió que la integración pasaba por la conexión y necesidad de estar integrado a un conjunto de redes para existir socialmente y generar beneficios en la vida cotidiana. Por tanto, esta lógica indagó las posibilidades que los jóvenes tenían de procurarse sentido mediante los usos que hacían de la red socio digital Facebook, los recursos que empleaban para conectarse y las dificultades que enfrentaban dadas las condiciones offline/online. Se consideró para el estudio en la lógica de la integración: la vida social (relación con los otros, uno mismo, la familia, la pareja) y los grupos (grupos de trabajo, comunidad académica, empleo).

La lógica estratégica apunta al conjunto de tácticas que denotan un amplio espacio de juego en el sujeto. Es esta la lógica en la que los individuos emplean una serie de estrategias para movilizar y negociar recursos, obtener prestigio, ganancia y rentabilidad, desarrollando un amplio sentido de la oportunidad. En este sentido, el estudio observó cómo a través de la manera en que los jóvenes universitarios resolvían la presentación de sí mismos, mediante los contenidos publicados en sus perfiles virtuales y el tipo de vínculos que establecían en la red socio digital Facebook, estos ejecutaban una serie de mecanismos de acción y desempeño para gestionar; por un lado, emergencias de la cotidianidad, organizar tareas, optimizar tiempos y, por el otro lado, definir mejor las acciones de unos hacia otros para garantizarse un flujo de información constante, comentarios, contactos, un "me gusta", etc. Se indagó en la habilidad de cada joven para "hacer movimientos" en la red y generarse beneficios en la vida offline y online.

La lógica de la subjetivación, por su parte, tiene que ver con la construcción del sujeto como tal. Se trata de un trabajo que se da entre los ideales y la experiencia social, entre los proyectos personales y las limitaciones de la propia existencia (Araujo \& Martuccelli, 2010). Es un sujeto que no es en efecto "puramente normativo" sino que también es el resultado final del trabajo que

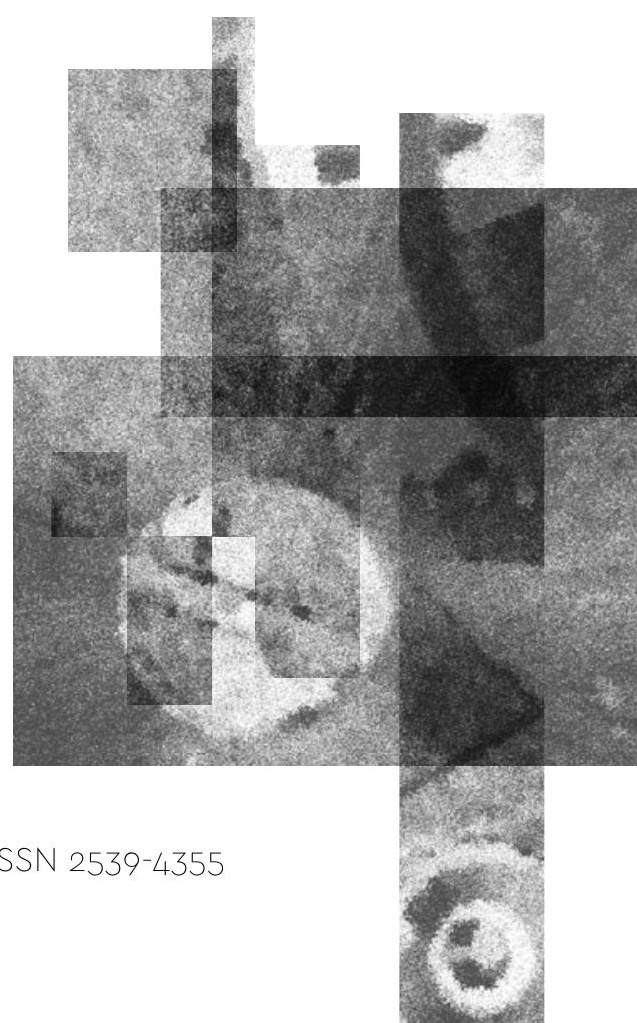


sin pretensión o de manera calculada hace sobre sí mismo frente a las dificultades que se le atraviesan (Unás, 2015). Por tanto, para el estudió se indagó sobre el reconocimiento de "sí mismo" que realizaban los jóvenes en sus perfiles virtuales (mundo online), considerando que esta forma de presentación se daba de manera reflexiva y crítica. En este sentido, se generó una tipología de jóvenes universitarios en la red socio digital Facebook, a partir de las formas de expresión y presentación que realizaban en sus perfiles virtuales.

El siguiente esquema Figura 1 representa la manera en la que se articulan las tres lógicas de acción en la experiencia de los jóvenes que usan Facebook (el vínculo causal en color naranja, la manera en la que se manifiesta en Facebook en color verde, las lógicas de acción en color azul).

Figura 1. Experiencia de Jóvenes en Facebook Fuente: Elaboración propia basada en el trabajo de Dubet (2010)

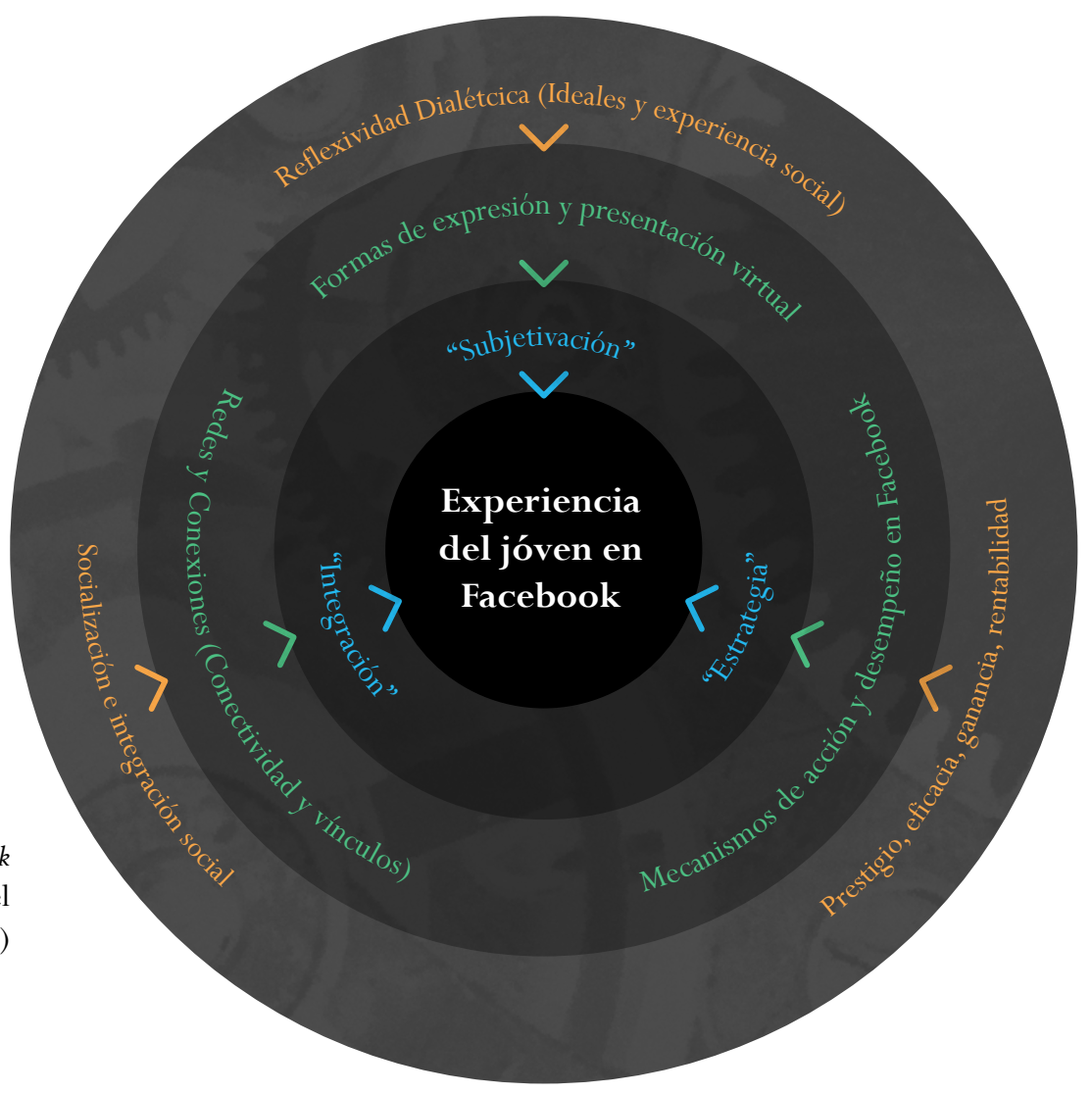

\section{Lógicas de acción online de los jóvenes en Facebook}

A lo largo de este apartado se presentarán los hallazgos de la investigación que llevaron a plantear la hipótesis de que los jóvenes universitarios residentes en la ciudad de Cali son unos individuos "conectados" que se procuran experiencias con sentido mediante la construcción de vínculos, formas de presentación y usos de Facebook para garantizarse beneficios. De esta manera, logran atenuar malestares urbanos contemporáneos de la vida cotidiana (soledad, angustia, aburrimiento, relación consigo mismo, universidad, familia, ciudad). 
La información recolectada de los participantes del estudio, al relacionarse con las lógicas de acción, permitió identificar que la experiencia de los jóvenes con la red socio digital se configuraba en torno a una serie de aspectos y procesos que ellos consideraban relevantes. Para la lógica de integración se encontró como significativo los grupos, el entretenimiento y la conexión que generaba la red. Para la lógica de la estrategia se identificó una serie de decisiones que toman los estudiantes de manera calculada, en ocasiones, y en otros casos la toma de decisión se daba por la experiencia de uso de Facebook que generaba maneras de operar. En la lógica de la subjetivación emergieron maneras de presentarse en la red socio digital de acuerdo al tipo de actividad de los jóvenes mostrando que estas no se daban de manera estática, sino más bien de forma dinámica y cambiante. A continuación, una explicación de los hallazgos en los apartados: a) la integración y sus dinámicas online; b) Toma de decisiones estratégicas en la red socio digital; c) Formas presentación y de expresión.

\section{a) La integración y sus dinámicas online: grupos, entretenimiento, conexión, actualización y regulaciones de la privacidad}

La apropiación de la red social Facebook se basa en las relaciones afectivas que establecen los jóvenes con otros usuarios de la red social. Dentro de estas se destacan los amigos con los que se construyen un tipo de prácticas y dinámicas que podrían considerarse "adecuadas" dentro de estos espacios virtuales (Lemus, 2017). Por ejemplo, los jóvenes se vinculan a grupos y fan pages a partir de sus gustos, intereses o identificaciones, en los cuales se configuran internamente los contenidos que pueden ser publicados para garantizar el éxito de la audiencia de un meme ${ }^{6}$ (Moreno, 2020), con quién relacionarse, cómo mostrarse, entre otras acciones (Benitez et al., 2016). Estas regulaciones se vinculan a las formas de actuar y presentarse que están habilitadas —o inhabilitadas — en las prácticas juveniles offline en la búsqueda de reconocimiento y de construcción identitaria para ser parte del grupo (Morduchowicz, 2012), para no ser excluidos de ciertos tipos de sociabilidad, así como para la gestión de recreación y entretenimiento (Gómez et al., 2016).

Junto con estos hallazgos, en el presente trabajo hemos registrado otros elementos que configuran la integración de los jóvenes a las redes socio digitales. Los perfiles virtuales indagados establecen vínculos con otros jóvenes universitarios o pareja, y aunque el contacto con los familiares existe, este es muy bajo. Se sostiene, entonces, retomando los aportes de Singly (Citado en Martuccelli \& Singly, 2012, p. 70) en relación al proceso de individualización en la adolescencia que muchos jóvenes no consideran - o consideran menos- a sus padres, pues toman distancia de sus pertenencias heredadas para explorar nuevas dimensiones y lazos. Por tanto, uno de los aspectos más significativos de la integración en Facebook es la posibilidad de que los jóvenes construyan intereses de forma individual sin depender de sus padres. En este sentido, una joven mencionó respecto a sus vínculos en la red socio digital: 
El círculo de amistades que tengo son compañeros de universidad, del colegio que seguimos en contacto y pocos familiares. (Valentina, 19, grupo focal en Universidad del Valle, marzo 29 de 2017).

En cuanto a los contenidos que generan diversión y entretenimiento en Facebook, estos no siempre son publicaciones políticamente correctas; en ocasiones se difunden contenidos que podrían ser inmorales y/o paradójicos. Los jóvenes pueden realizar publicaciones en las que manifiesten cierta militancia política, ambientalista, animalista, entre otros; y al mismo tiempo pueden divertirse con publicaciones que movilicen cierto tipo de acoso, humor negro, actitudes sexistas o machistas. De ninguna manera este tipo de comportamiento hace conflicto de sentidos en los jóvenes, ya que cada uno de ellos, acorde a sus biografías, construye unas subjetividades a partir de los mundos de la vida que habitan y de sus relaciones con los otros, mediadas o no por las tecnologías que les procuran sentido y movilizan en ellos las posibles publicaciones en sus perfiles. Los jóvenes producen contenidos que "representan la realidad en la que viven de forma divertida, creativa o al menos heterodoxa, a diferencia de lo que usualmente se les exige en el ámbito escolar donde la comunicación dominante es a partir de texto, en tono formal" (Moreno, 2020, p.192). En relación con lo mencionado una joven señaló:

Grupo focal: Ángela, ¿qué grupos tienes en Facebook?

Ángela: El de Confecciones y Capuchos unlimited $1.0^{7}$ es chévere, me gusta ese humor negro. A mi carrera le tiran mucho, le hacen burlas. Pero igual es parte de la dinámica de la perspectiva del grupo, hacer bullying, humor (Grupo focal en Universidad del Valle, marzo 29 de 2017).

La integración a la red social Facebook permite la gestión de lazos de pertenencia a grupos y entretenimiento. Sin embargo, esta vinculación está directamente relacionada con una necesidad de conexión y actualización constante (Reguillo, 2012). Los jóvenes participantes del estudio manifestaron que implementaban una serie de recursos para estar conectados, tales como pagar un plan de datos o conectarse a una señal de wifi desde sus dispositivos móviles. En este sentido, una de las jóvenes expresó:

Bueno, la conexión básicamente es plan de datos en el celular, o básicamente cuando no tengo datos me toca llegar a la casa a coger el portátil, pero si tengo Wifi obviamente lo utilizo. (Lina, 23, Universidad San Martin. Entrevista, 2017).

En la actualidad, la conexión es permanente y no se requiere estar frente al computador en casa para entrar a un perfil virtual (Pérez \& Montoya Gastelún, 2020). Los jóvenes pueden estar actualizados de lo que pasa de manera inmediata; por lo tanto, estar conectado y actualizado les posibilita "estar enterados", "estar informados", "tener contacto". En cuanto a esto, es importante considerar que los jóvenes piensan que enterarse de un suceso en Facebook, o ver un video en vivo por 
la red socio digital, es estar informado. Sin embargo, muchas veces acceden a la información sin comprender los contextos en los que estos se producen o las implicaciones que tienen. Sumado a esto, la información a la que acceden los jóvenes es la que sus contactos circulan por la red, que en ocasiones puede ser falsa (Fake news). Por tanto, los contenidos ya tienen un filtro y los jóvenes no se enteran de todo como algunos suelen pensar. Tal vez sea importante considerar la posibilidad de fomentar un pensamiento crítico como motor de acción de todo individuo que lleve a tener una postura distante y reflexiva sobre la calidad de los contenidos aportados por la web (Grosso , 2011).

También, en ocasiones la experiencia de conectividad puede llevar a que los jóvenes activen los mecanismos de privacidad y seguridad, debido a los efectos sobre su realidad offline, así como a que tengan en cuenta qué tipo de información publican en su perfil. Se puede decir que los jóvenes en sus perfiles virtuales de Facebook hacen uso de su reflexividad al publicar. Por tanto, al momento de realizar una acción en su muro los jóvenes seleccionan qué tipo de información compartir para sortear los problemas que establecen los límites de lo público/privado, y dotar de coherencia y sentido su experiencia con la red socio digital Facebook. Los jóvenes no realizan publicaciones de manera inconsciente en sus perfiles. Antes de publicar cada joven realiza un proceso de revisión detallada al tipo de publicación que subirá a su perfil, mira la foto que va postear, la ortografía del comentario y la audiencia a la que lo va a compartir. Respecto a su información compartida en su perfil una joven comentó:

Como uno construye una imagen de uno allí, soy muy cuidadosa con lo que monto y con las cosas que pueden ver mis amigos de Facebook. (Mariana, 24, grupo focal en Universidad del Valle, marzo 29 de 2017).

Estar integrado a Facebook parte del reconocimiento de las posibilidades que tiene la red social, los vínculos que establecen los jóvenes universitarios dentro de ella, así como por las consecuencias que deben sobrellevar por el hecho de mantenerse conectados y constantemente actualizados.

\section{b) Toma de decisiones estratégicas en la red socio digital: tácticas de prestigio, acción y desempeño de jóvenes en Facebook}

El estudio identificó que las publicaciones de los jóvenes, aunque tienen un proceso premeditado, son susceptibles a efectos inesperados, no calculados, y por tanto los jóvenes aprenden por el uso de la plataforma a anticiparimprevistos de una publicación, de la información que circula y las solicitudes de amistad que aceptan. En este sentido, es 
probable que las acciones en la red socio digital puedan ser racionalizadas para la búsqueda de logros óptimos, en tanto los jóvenes pueden elegir estratégicamente qué satisface mejor sus deseos. En este sentido, la decisión racional en Facebook parte de la repetición a diario de acciones en la red, lo cual guarda estrecha similitud con el concepto de rutinización definido por Giddens (1995), pues según el autor "la rutinización es vital para los mecanismos psicológicos mediante los cuales un sentido de confianza o de seguridad ontológica es sustentado en las actividades prácticas de la vida social" (Giddens , 1995, p. 24). Esto es, que la repetición cotidiana del uso de Facebook, en tanto práctica social de los jóvenes posibilita la reflexividad de ellos en las acciones de sus perfiles virtuales.

Por consiguiente, hablamos de que emergen en los usos de la red socio digital que hacen los jóvenes unas tácticas de prestigio, acción y desempeño. En cuanto a las tácticas de acción y desempeño se puede decir que estas no sólo encierran vínculos emocionales o relacionales, sino que tratan también de gestionar emergencias de la cotidianidad, buscar eficacia de tareas y optimización del tiempo. Es la búsqueda de un buen desempeño y/o la multiplicación de las posibilidades de acción al estar conectado. Según Jaurégüiberry \& Proulx (2011) "Le fait de pouvoir être, par l'écoute et la parole, dan deux voire trois endroits à la fois, découple les possibilités d'action, donc de gains éventuels'8 (Jaurégüiberry \& Proulx, 2011, p.109). Por tanto, se trata de un tipo de comunicación racional instrumental y utilitarista de la propia acción dentro de la red para definir mejor las acciones de unos hacia los otros, considerando a los contactos un potencial recurso para ejecutar movimientos hacia beneficios ocasionales.

Durante la observación de los perfiles virtuales y los relatos de los participantes en las entrevistas, grupo focal y conversaciones por chat, se identificó que los jóvenes realizaban publicaciones que buscaban difundir un mensaje a varias personas en tiempo real por sus beneficios individuales o colectivos. De este modo ahorraban tiempo, dinero y obtenían una respuesta inmediata. Esto pasaba por los grupos a los que ellos se encontraban vinculados o por los muros de sus perfiles virtuales en menor medida. Por ejemplo, una de las jóvenes manifestó respecto a las posibilidades de gestionar emergencias universitarias por Facebook debido a sus ventajas comunicativas:

"En el grupo si hay alguna duda, alguna inquietud, alguna información que dar, siempre la postean, entonces digamos que ha facilitado un poco la comunicación” (Daniela Peña, 23. Universidad Cooperativa. Entrevista, 2017).

Mediante los grupos a los que los jóvenes se adhieren se difunden mensajes a varias personas de manera simultánea. Esto multiplica las posibilidades de acción y ahorra tiempo al momento de tratar de comunicar una información a muchos contactos. 
Es más económico rotar información por la red socio digital porque llega a más personas de manera más rápida y en tiempo real con una sola acción, mediante un mensaje vía chat grupal, una publicación en un perfil o un grupo. Tratar de ubicar a muchas personas de manera independiente a través de llamadas telefónicas o mensajes individuales requeriría realizar más acciones y repetir la información una y otra vez, lo cual sería agotador y desgastante.

Además, fue importante ver cómo los contactos de los jóvenes en Facebook son tenidos en cuenta como recursos según el conjunto de sus características y potencialidades. Esto permite calcular la capacidad de respuestas afirmativas dependiendo de los intereses con los que los jóvenes realicen sus publicaciones. Facebook se vuelve un mecanismo conductivo para ampliar y reconfigurar el capital social (Coleman, 1986) de los jóvenes universitarios, pues en el uso de la red socio digital los jóvenes en algún sentido están acumulando y retejiendo sus existentes (y preexistentes) volúmenes de capital social (entre otros), lo cual los lleva a satisfacer sus intereses y puede influir o no en los usos estratégicos que hacen de Facebook. En relación a esto una estudiante de medicina expresó:

"En este gremio pues uno tiene que tener muchos colegas porque a veces son importantes para que lo ayuden a uno a ingresar a un hospital...yo los agrego porque van en un nivel mucho más avanzado que uno y de pronto uno necesite algo de ellos" (Lina, 23, Universidad San Martin. Entrevista, 2017).

Así mismo, emergen unas tácticas de prestigio ${ }^{9}$ al no reducir la lógica estratégica solo a la búsqueda de oportunidades abiertas por la comunicación instrumental que hacen los jóvenes en Facebook. También los jóvenes participan de interacciones puramente sociales y de conductas más banales como placer y reconocimiento. No obstante, esto no significa que los jóvenes en tanto individuos sean unos "puros egocéntricos"; simplemente orientan sus acciones a partir del análisis que realizan de la plataforma en la búsqueda de posibilidades de acción para obtener ganancias acordes a sus intereses.

Un ejemplo de esto es la opción del like ${ }^{10}$, pues, aunque los jóvenes del estudio manifestaron que no era una respuesta que buscaban de manera explícita al realizar una publicación, el que estas tuvieran reacciones y/o comentarios les generaba un sentimiento de satisfacción ${ }^{11}$. Respecto a esto uno de los jóvenes entrevistados expresó:

"La verdad es chévere ver que cada foto tiene 150 o 200 likes y no es que yo sea reconocido, pero tengo mucha gente de voleibol (...) que me da "likes" (...) mucha gente observa mis publicaciones (...) y se va creando poco a poco "fama”, un prestigio. (Sebastián, 21, Escuela Nacional del Deporte. Entrevista, 2017). 
Del mismo modo, uno de los hallazgos del ejercicio de investigación fue que, aunque la red socio digital ha venido siendo desplazada por otras redes, Facebook es central para los jóvenes que administran páginas y grupos. Para ellos la actividad en las redes socio digitales es como un tipo de trabajo o compromiso social adquirido con sus seguidores, por lo que el juego del prestigio está presente en sus actividades constantemente. Esto implica "pensar una situación común experimentada por la audiencia y aprovecharla para ganar likes y otras formas de reconocimiento, como el aumento de seguidores a través de estos contenidos" (Moreno, 2020, p.187). Un joven mencionaba que para él la información le daba un tipo de "poder" al ser consultado por sus contactos acerca de la dinámica universitaria:

\begin{abstract}
Yo considero que estar informado es importante porque genera algún poder con respecto a otros compañeros que no están tan conectados con la red, entonces, cuando sucede algo todos recurren a preguntarme a mí, ¿hay Central? ¿Hay bloqueo? ¿Está el profesor?Ya me gané la fama de estar conectado siempre. (Julián, 21, grupo focal en Universidad delValle, marzo 29 de 2017).
\end{abstract}

En este sentido, se considera que este consumo de prestigio es atribuible a la actividad que realizan los jóvenes en sus perfiles virtuales de Facebook; en tanto que, por sus actividades online, tienden a ser reconocidos por los demás usuarios quienes valoran el contenido que publican y la información que manejan.

Por consiguiente, estas tácticas de prestigio, acción y desempeño corresponden a una serie de racionalidad deliberada que se origina a partir de la relación de eficacia, ganancia y rentabilidad entre objetivos y medios. Es decir, a partir de los contactos que los jóvenes tienen en sus perfiles virtuales y de lo que les permite hacer Facebook. Por tanto, en estas acciones estratégicas los jóvenes buscan un reconocimiento de sí mismos para el establecimiento de relaciones satisfactorias, por lo que no solo hay un interés instrumental sino también la búsqueda de encuentros y vínculos, en tanto soportes existenciales, que ayuden a llevar tensiones de la sociedad. En este sentido, lo que importa es que los jóvenes, haciendo uso de sus contactos y de las posibilidades que les permite Facebook, definan sus posibilidades de acción (gestionar una emergencia cotidiana, establecer vínculos, ganar un like, etc.), analicen las consecuencias y ventajas, escojan la opción más racional, implementen la decisión y evalúen, de manera que los resultados sean favorables y óptimos para sus intereses en la vida online/offline sin que esto afecte sus presentaciones en la red socio digital y sus vínculos. 
c) Formas de presentación y de expresión: lógicas de subjetivación de los jóvenes en Facebook

Dentro de los espacios que tiene la red socio digital Facebook, es tal vez la biografía, el lugar en el cual un individuo se revela en internet, a fin de obtener una validación pública de sí mismo o desplegar una parte de sí que, en su estatus o en su posición social, se hace difícil o imposible de expresar. La biografía puede ser el lugar que le permite al individuo habitar y desarrollar dimensiones de su personalidad que han sido contrariadas y frustradas dentro de su entorno social, como también dar cuenta de pequeños fragmentos de la vida, que a modo de crónica de la cotidianidad, muestran el devenir de su existencia.

En este sentido, parte de la subjetividad de los individuos en la red socio digital Facebook se constituye en perfiles virtuales al establecer reflexiones consigo mismos, con las imágenes de sí, la vida cotidiana y la vida universitaria. A través de las imágenes, comentarios, fotografías, videos y demás publicaciones en sus biografías, los jóvenes presentan su subjetividad buscando “(de alguna manera) impactar en otros: narrar la vida cotidiana, divulgar temas, crear controversia, generar opinión pública, llamar la atención, divertir, provocar" (Gómez R. , 2014, p. 237). También "los dispositivos digitales, como los teléfonos móviles, inscriben nuestros mensajes, interacciones, conexiones, contactos, movimientos, ideas, sentimientos y apariencia física, al tiempo que contribuyen a inscribir, configurar y rastrear afectos, relaciones y subjetividades" (Lasén Díaz, 2019, p. 315). Gracias a esta posibilidad de inscripción, las redes socio digitales dan cuenta de aspectos de la subjetividad de los jóvenes mediante sus formas de presentación. Así mismo, este trabajo en la red socio digital es un "trabajo liberado" (Gómez \& Gonzáles, 2013) que no produce réditos sino un tipo de realización plena del ser humano por fuera de las lógicas del mercado capitalista que les da una manera de resistir y administrar la impotencia que conlleva la soledad, el aburrimiento, el riesgo y la incertidumbre de la sociedad actual, mediante la posibilidad de actuar y operar eficazmente en sus perfiles virtuales, generándose un cierto soporte existencial.

Por consiguiente, en relación con las aportaciones de Gómez \& Gonzáles (2013), se encontró en las páginas virtuales de los jóvenes del estudio, cuatro tipos de comportamiento que constituyen unos perfiles que no son estáticos, sino más bien dinámicos y cambiantes:los jóvenes al presentarse en la red socio digital pueden pasar de un perfil a otro. Estos perfiles constituirían un tipo de cultura política de resistencia a las consecuencias del capitalismo informacional, abriendo una brecha para el encuentro y la construcción de vínculos desde las posibilidades de encuentro y creatividad que permite la red socio digital. 
* Prosumers e intertextualidad: Un joven universitario cuyos contenidos compartidos en sus publicaciones parten del intercambio de información en Facebook con sus contactos. Es productor y consumidor de contenidos digitales que giran en torno a sus profesiones, gustos e intereses, situaciones mediáticas y memes. Se traslada entre las páginas, perfiles virtuales de sus contactos, o el motor de búsqueda Google buscando la información que posteriormente será parte de sus publicaciones. Su subjetividad gira en torno a "mostrar y compartir contenidos que se producen en la red".

* La expresión del yo y la estética: un joven universitario cuyas publicaciones, por un lado, se relacionan con propuestas de color, concepto, efectos, fotografías, tratamiento y escenificación en las imágenes que comparte. En estas imágenes la intimidad puede ser reflexiva (exposición estética del cuerpo). Por otro lado, está el despliegue de datos personales, comentarios, narraciones de la vida cotidiana, saberes y creencias con las que los jóvenes sienten un grado de correspondencia. Su subjetividad lleva la premisa "expresar mi forma de ser y de relacionarme con el mundo".

* Lo emocional y el vínculo: un joven universitario que moviliza un tipo de emociones y vínculos afectivos en sus publicaciones, contribuyendo a sostener un tipo de arquitectura emocional. Su muro de Facebook es usado como una especie de diario público para la expresión de sus estados de ánimo, incertidumbres o preocupaciones, haciendo partícipes a los demás usuarios de la red socio digital de los sucesos alegres o tristes que puede estar viviendo en su cotidianidad. Es un joven universitario cuya subjetividad encierra la premisa "publicar para que mis contactos vean".

* Derivas políticas: un joven universitario que produce contenidos subjetivos, usando su perfil virtual como una especie de estrado desde el cual realiza denuncias públicas, crea conciencia, o llama a un tipo de movilización. Su perfil funciona como un lugar para convocar y generar disputas en lo público, pues es un tipo de caudillo que se favorece de las posibilidades de difusión y espacio de creación estética de la plataforma virtual para compartir contenidos de su interés, en cuanto a problemáticas económicas, sociales o políticas de la ciudad, el país y el mundo. Su subjetividad apunta a "usar Facebook como una forma de hacer crítica".

Cabe aclarar que el tipo de publicaciones en los jóvenes y el tipo de actividad en los perfiles tiende a variar según sus vínculos, estados de ánimo, profesiones, género, intereses, etc. Esto hace que los jóvenes en sus perfiles tengan diferentes usos y transformaciones que se dan acorde con su trayectoria de vida, los espacios de socialización y la relación que establecen con las instituciones (colegio, universidad, empresa) $\mathrm{u}$ otras redes socio digitales. Por tanto, los jóvenes se mantienen integrados a Facebook, pero el uso de la plataforma cambia según su edad y sus nuevos intereses personales. También, el uso de Facebook es volcado a nuevas actividades por el mercado y los valores de esta sociedad de consumo que llevan a la necesidad de estar conectado constantemente en las redes socio digitales, capturando el deseo y la necesidad de exploración de la subjetividad, para crear necesidades y ofrecer opciones para elección y consumo. 
Para los participantes, una cosa era usar Facebook en el colegio, otra en la universidad y otra muy distinta será después de graduarse, pues es posible que este sea usado para solo entretenimiento o para establecer contactos laborales. Una vez llegan a la vida universitaria, los jóvenes pueden pasar de la publicación de fotografías de sí mismos o eventos personales a publicaciones de tipo crítico, social e informativo, o simplemente dar like a las publicaciones de sus contactos y compartir información en su muro u otros perfiles virtuales y grupos. Los espacios virtuales se vuelven lugares propicios para expresar sus opiniones, comunicar temas de su interés o entretenerse. En este sentido, la construcción de subjetividad está en la posibilidad de explorar la construcción de las posibilidades de la red socio digital, los mundos de la vida que habitan los jóvenes y la sociedad de consumo que difunde información por la web.

\section{Conclusiones}

Con la intención de contribuir al conocimiento del tipo de individuo que se está formando entre los jóvenes universitarios residentes en la ciudad de Cali a partir de la experiencia con las tecnologías, el análisis de la relación de los jóvenes con la red socio digital Facebook permite sugerir que:

La red socio digital Facebook en tanto soporte, en el sentido Martucceliano, es en sí misma un espacio que atenúa los malestares urbanos contemporáneos de la vida cotidiana de los jóvenes (soledad, angustia, aburrimiento, relación consigo mismo, universidad, la familia y la ciudad) al permitirles un lugar de anclaje en el que articulan lógicas de acción con sentido (integración, estrategia, subjetivación).

El joven universitario es un individuo integrado al uso de los dispositivos digitales y las redes socio digitales, que se procura entretenimiento y maneras de relacionarse creando paradojas entre lo políticamente correcto e incorrecto socialmente. Por tanto, el joven universitario también deriva goce en el publicar y compartir información para su diversión; en esas acciones que realiza por el placer que en sí mismas producen. Es un joven que cree que está informado por el acceso constante de información y en ocasiones puede considerar que esta lo coloca en un lugar de prestigio sobre sus demás contactos, sin que sea necesariamente cierto pues la percepción que él tiene de sí mismo puede variar de las percepciones de los demás. Sin embargo, este prestigio termina siendo importante para algunos jóvenes en Facebook, aunque la red socio digital haya perdido importancia en la actualidad por el uso de otras (WhatsApp, Instagram, Snapchat), sigue siendo central para aquellos jóvenes que administran fan pages o grupos, y requieren mantener su rol de reconocimiento social.

Así mismo, es un individuo que por los beneficios de la conectividad se procura acciones que pueden ser racionalizadas, o no, para la búsqueda de logros óptimos, en tanto los jóvenes pueden elegir estratégicamente las tácticas de acción y desempeño 
que mejor satisfacen sus deseos; los cuales, como se ha mencionado, pueden estar en la satisfacción adquirida por la obtención de likes, la solución de emergencias de su cotidianidad, así como establecer vínculos, etc. También, el joven universitario tiene una necesidad de conexión constante a las redes socio digitales en donde sus espacios de socialización, el mercado y los valores de esta sociedad de consumo capturan su deseo y necesidad de exploración de la subjetividad, llevándolo a usos cambiantes que alteran sus maneras de presentación en Facebook. Podría decirse que es un individuo que vive en una sociedad de la transparencia (Han, 2013), en la que los límites de lo privado y lo público se matizan, y su presentación de sí mismo cada vez es más reflexiva, en Facebook crea y mantiene una cuenta con imágenes que exponen la estética de su cuerpo, sus datos personales e información real al tiempo que activa ciertos mecanismos de privacidad para cuidar su integridad.

Finalmente cabe mencionar que Facebook, como otras redes socio digitales en las que jóvenes invierten su tiempo, se convierte en un espacio que les permite narrar acontecimientos de la vida, para hacerse a experiencias en medio de la sociedad de la información actual que procura velocidad e inmediatez, lo cual puede ser atribuible a la manera en que las personas invierten tiempo en otras actividades cotidianas offline de entretenimiento (lectura, deportes, cine, paseos) para procurarse soportes a la incertidumbre.

Con estos hallazgos se espera haber contribuido a la comprensión de las características y modalidades que adquieren los procesos de individuación de los jóvenes universitarios hoy en día, desde el uso de la tecnología, como reveladora de las tensiones y retos de nuestra sociedad inmersa en el riesgo, en la que requerimos constantemente la creación de soportes existenciales; como el uso de las redes socio digitales para atenuar nuestros malestares contemporáneos.

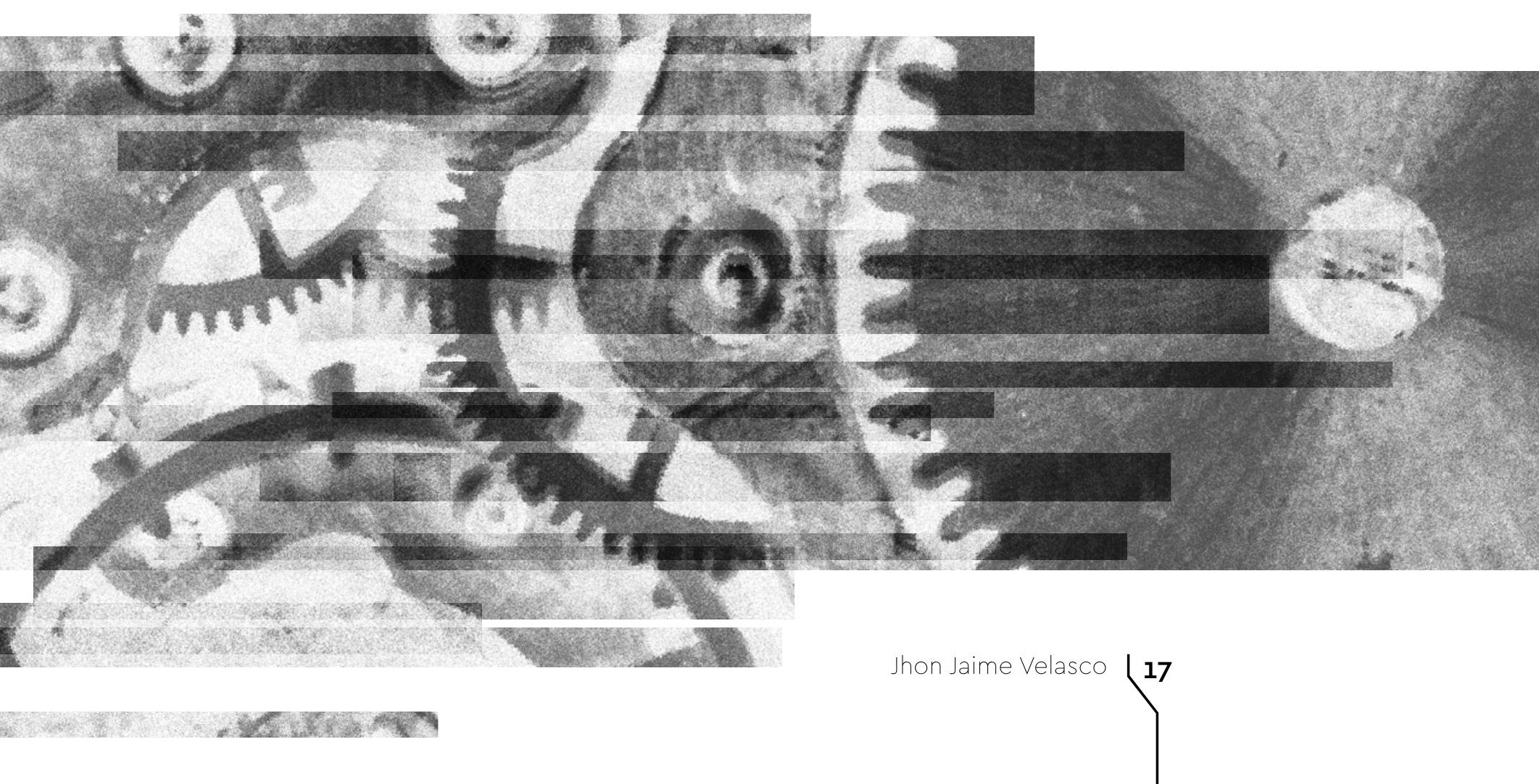


Hine, C. (2000). Etnografía virtual. Editorial UOC.

Hine, C. (2015). Ethnography for the internet: embedded, embodied and every day. Bloomsbury Publishing. Jaurégüiberry, F. \& Proulx, S. (2011). Usages et enjeux des technologies de communication. Érès

Lasén Díaz, A. (2019). Lo ordinario digital: digitalización de la vida cotidiana como forma de trabajo. Cuadernos de Relaciones Laborales, 37(2), 313-330. https://revistas.ucm.es/index.php/CRLA/article/view/66040

Lemus, M. (2017). Jóvenes frente al mundo: las tecnologías digitales como soporte de la vida cotidiana. Revista Latinoamericana de Ciencias Sociales, Niñez y Juventud, 15, 161-172. http: / / revistaumanizales.cinde.org.co/rlcsnj/index.php/Revista-Latinoamericana/ article/view/2955

Martuccelli, D. (2007). Cambio de rumbo. La sociedad a escala del individuo. Lom Ediciones.

Martuccelli, D. \& Singly, F. (2012). Las sociologías del individuo. Lom Ediciones.

Morduchowicz, R. (2012). Los adolescentes y las redes sociales. La construcción de la identidad juvenil en Internet. Fondo de Cultura Económica.

Moreno, A. (2020). Memes de Internet, remediaciones entre nosotros y la otredad. Revista de Estudios Sobre Juventud, (35), 177-199. https://revistajovenes.imjuventud.gob.mx/index.php/ inicio/descargar/3

Pérez, E. \& Montoya Gastelún, G. (2020). Jóvenes entre plataformas sociodigitales. Universidad Nacional Autónoma de México.

Pink, S., Horst, H., Postill, J., Hjorth, L., Lewis, T. \& Tacchi, J. (2019). Etnografía digital. Ediciones Morata.

Reguillo, R. (2012). Navegaciones errantes. De músicas, jóvenes y redes: de Facebook a Youtube y viceversa. Comunicación y sociedad, (18), 135-171. http://www.comunicacionysociedad. cucsh.udg.mx/index.php/comsoc/article/view/194

Serrano, J. (2012). La presentación de la persona en las redes sociales: una aproximación desde la obra de Goffman. Anàlisi, (46), 1-17. https://dialnet.unirioja.es/servlet/ articulo? codigo $=4131374$

Sibila, P. (2008). La intimidad como espectáculo. Fondo de Cultura Económica.

Turkle, S. (2011). Alone together: why we expect more from technology and less from each other. Basic books. Unás, V. (2015). Vida, trabajo y amor. Profesores en contextos inciertos. Universidad Icesi.

Winocur, R. (2012). Transformaciones en el espacio público y privado. La intimidad de los jóvenes en las redes sociales. Revista TELOS, (91), 1-9. https://telos.fundaciontelefonica.com/ archivo/numero091/

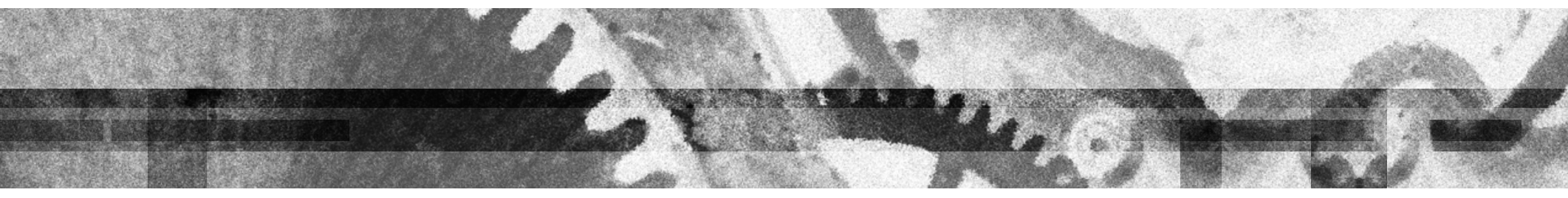

Notas

${ }^{1}$ Profesional en Recreación y Magíster en Sociología de la Universidad del Valle. Profesor de la misma universidad en la Facultad de Educación y Pedagogía. Es integrante de la línea de investigación Recreación, Intersubjetividades e Interculturalidad adscrita al Grupo de Investigación de Educación Popular de la Universidad del Valle.

${ }^{2}$ Siguiendo a Pérez \& Montoya Gastelún (2020) en este artículo se decide usar el concepto de redes socio digitales en lugar de redes sociales, porque se considera que estas ultimas se establecen independientemente de las tecnologías. Además, la noción socio digital refuerza la intención de dar cuenta de los procesos de socialización que se dan entre quienes las utilizan y los significados que se construyen alrededor de estas. 
${ }^{3}$ Martuccelli (2007) plantea la necesidad de establecer el estudio de las capacidades existenciales y sociales del individuo de sostenerse en el mundo. Indica que no hay individuo capaz de sostenerse sin un conjunto muy importante de soportes, materiales y/o simbólicos, que se desplieguen en su experiencia biográfica, a través de un entramado de vínculos con sus entornos sociales e institucionales.

${ }^{4}$ La prueba es un importante instrumento analítico en los estudios de la sociología del individuo, en la medida que propone una articulación entre el actor y el sistema tras la crisis de la idea de sociedad. Para la presente investigación se retoman los planteamientos de Araujo y Martuccelli (2010) para quienes la prueba se presenta como un desafío que los individuos enfrentan en un momento histórico determinado.

${ }^{5}$ Cabe indicar que Hine (2015) y diversos autores como Gómez Cruz (2017), Pink et al. (2019) en estudios recientes acuñan el concepto etnografía digital para referirse a investigaciones de internet atravesadas por lo digital que intentan ir más allá de aquello que se ve en la superficie y articulan lo digital como objeto e instrumento de la investigación. Este estudio, aunque profundizó en lo que se veía más allá de los perfiles virtuales de los jóvenes para tratar de explicar su actividad online, se reconoce como una etnografía virtual al no ampliar en este aspecto.

${ }^{6}$ Según Moreno (2020) "Los memes de Internet son objetos digitales que toman la forma de imágenes, videos, audio, animaciones u otros formatos de archivo, en los que se mezclan contenidos provenientes de la cultura popular y las industrias culturales para formar nuevos contenidos, que circulan en internet, sirven para hacer bromas y burlas o para discutir distintas perspectivas, para denunciar injusticias o reírse de ellas, para reforzar estereotipos o ponerlos en duda a través del humor" (Moreno, 2020, p. 178)

${ }^{7}$ En el grupo de Facebook la palabra "confesiones" presenta un error ortográfico. Se mantuvo el nombre original del grupo mencionado en la trascripción.

8 "El hecho de poder estar, por medio de la escucha y la palabra, en tres lugares a la vez, multiplica las posibilidades de acción y de ganancias eventuales" (Traducción elaborada para este trabajo).

${ }^{9}$ Esta sensación de prestigio podría entenderse desde el planteamiento de Norbert Elías (1996) en la sociedad cortesana. Él advertía retomando el concepto presentado por Veblen acerca de la sociedad de "conspicuous consumption" (consumo para provocar admiración), que toda forma que pertenecía a un hombre tenía un valor social de representación y era un instrumento indispensable de autoafirmación social. En esta sociedad se libraba una incesante lucha de competencia por las oportunidades de estatus y prestigio.

10 "Reacción" que se otorga a través del botón Me gusta en Facebook para de alguna manera "validar" la información de la publicación.

${ }^{11}$ Por otra parte, cabe anotar que existen perfiles públicos de jóvenes quienes realizan estrategias comerciales en los que se evidencia un interés por movilizar un tipo de prestigio. Para estos personajes su actividad en redes sí está destinada a este fin, pues hacen parte de una nueva manera de hacer publicidad y marketing por las redes sociales; ellos son influencer.

${ }^{12}$ Según Gómez \& Gonzáles (2013) "los jóvenes en las ciudades realizan inversiones de tiempo, deseo y trabajo en la elaboración de un tipo de obras y creaciones, bienes expresivos sin pretensiones, cuyo destino, gestión y alcance no están definidos ni por el ánimo de lucro, ni por un vínculo laboral que prescribe y obliga a realizar la obra” (Gómez \& Gonzáles, 2013, p. 70). En este sentido, para los autores el trabajo de cientos de personas en redes sociales como Facebook, Second life o plataformas de diseño 3d, es más un "trabajo liberado" de creación, movilizado más por el deseo y menos por las lógicas del mercado capitalista. Por tanto, la noción de trabajo liberado sería un lugar desde donde entender las acciones y creaciones que los jóvenes universitarios realizan en sus perfiles virtuales Facebook, para permitirse encuentros con otros y resistir a los malestares y consecuencias que les genera la vida cotidiana y la vida universitaria. 